\title{
Raban Maur, Poezje (wybór)
}

\author{
(Hrabani Mauri carmina)
}

\section{Wstęp}

Zajmujący się poezją średniowieczną nie potrafi ogarnąć jej ogromu, choćby wkładał w to wiele trudu. Musiałby przeczytać - jak wylicza ks. M. Starowieyski - 55 tomów Analecta hymnica, fragmenty poetyckie rozrzucone po 217 tomach Patrologii Łacińskiej Migne'a i 5 tomach Suplementu do jej pierwszych 96 tomów, dalej 9 tomów poezji wydanej w serii poetów Monumenta Germaniae Historica oraz dziesiątki wydań poszczególnych autorów, wydań czy zbiory inskrypcji ${ }^{1}$. Niewiele jest utworów wydanych krytycznie, a wciąż pozostają dzieła jeszcze niewydane ${ }^{2}$. Te zniechęcające (czy może przeciwnie - mimo wszystko zachęcające) uwagi M. Starowieyskiego każą nam w tym miejscu przyjrzeć się choćby trochę poezji Rabana Maura, któremu (wprawdzie tylko tradycyjnie) przypisuje się autorstwo hymnu Veni Creator.

Urodzony ok. 780 roku w Moguncji i doskonale wykształcony Raban Maur był wpływową postacią okresu odnowy karolińskiej. Już jako dziecko przygotowywał się do życia monastycznego w klasztorze w Fuldzie, wiedzę teologiczną i artes liberales pogłębił pod kierunkiem Alkuina, który dał mu przydomek Maurus (noszony przez ulubionego ucznia św. Benedykta). W 814 roku Raban otrzymał święcenia kapłańskie, w 822 roku został opatem klasztoru w Fuldzie, a 847 - arcybiskupem Moguncji. Zmarł w 856 roku. Był egzegetą, filozofem i poetą. W bogactwie dorobku teologicznego Rabana Maura znaczące miejsce zajmują wyjaśnienia egzegetyczne prawie wszystkich ksiąg Starego i Nowego Testamentu ${ }^{3}$ Jego twórczość poetycka zaś, wydana w Monumenta Germaniae Historica, obejmuje 97 utworów napisanych głównie heksametrem

1 Wstęp, w: Muza łacińska. Antologia poezji wczesnochrześcijańskiej i średniowiecznej (III-XIV/XV w.), opr. M. Starowieyski, Wrocław - Warszawa - Kraków 2007, XII.

2 Wstęp, s. XXIV.

3 F.W. Bautz, Hrabanus Maurus, w: Biographisch-Bibliographisches Kirchenlexikon (BBKL), t. 2, Hamm 1990, 1090-1093. 
lub metrum elegijnym. Są to utwory o rozmaitej tematyce, przede wszystkim okolicznościowe, dedykowane różnym adresatom, dalej opisy inskrypcji znajdujących się w kościołach oraz epitafia. Tuż za nimi w Monumenta Germaniae Historica znajduje się zawierający 19 utworów Appendix hymnorum incertae originis włączonych jednak do utworów Rabana pod takim samym tytułem jak poprzednie 97 - Hrabani Mauri carmina.

Niniejsze opracowanie zawiera pierwszy polski przekład szesnastu utworów spośród 97 autentycznych wierszy Rabana i czterech utworów incertae originis o tematyce ściśle liturgicznej, przypisanych wszakże temuż poecie. Przełożonych tu więc zostało stosunkowo dużo utworów, ale są one krótkie, wręcz bardzo krótkie, jak większość utworów karolińskiego poety. $\mathrm{W}$ ten sposób - sądzę - czytelnik nieznający tej twórczości zyska jakieś wyobrażenie o całości poezji Rabana Maura.

Wybrane utwory napisane zostały w różnych metrach starożytnych: jambicznym, trocheicznym, w heksametrze, w metrum elegijnym, wreszcie w asklepiadejskim mniejszym. Tłumacząc je na język polski, czynię to na różne sposoby, próbując znaleźć w ramach systemu polskiej wersyfikacji odpowiedniki ekwimetryczne. Dystych elegijny, a w tym metrum mamy tu dziesięć wierszy, to metrum niemające - jak wiadomo - polskiego odpowiednika ze względu na trudność oddawania pentametru. Ponieważ jednak przełożone utwory są bardzo krótkie, zdecydowałem się zastosować technikę, której nie można stosować absolutnie przy dłuższych wierszach ze względu na językową sztuczność przekładu, w którym zarówno przed średniówką, jak i na końcu wersu stawiałoby się wyraz jednosylabowy. Tak jednak tu uczyniłem, ufając, że krótkość przełożonych pomimo tej obiekcji wierszy nie zdąży podczas lektury zmęczyć ucha czytelnika, co stałoby się w przypadku wierszy dłuższych. Z całą pewnością chciałem tego w stopniu maksymalnie możliwym uniknąć.

\section{Wydania tekstu}

Migne J.P., Parisiis 1862: PL 112, 1583D-1650B (Carmina de diversis); PL 112, 1649C-1670A (Hymni); PL 112, 1669 -1676B (Epitaphia).

Hrabanus Maurus, Carmina, MGH Antiquitates. Poetae Latini medii aevi 2: Poetae Latini aevi Carolini, Berolini 1884, 154-258.

Analecta hymnica medii aevi. L. Hymographi Latini. Lateinische Hymnendichter des Mittelalters, red. G.M. Dreves - C. Blume, Leipzig 1907 (tylko niektóre utwory Rabana Maura). 


\subsection{Przekłady nowożytne}

Brak

\section{Bibliografia}

Bautz F.W., Hrabanus Maurus, w: Biographisch-Bibliographisches Kirchenlexikon (BBKL), t. 2, Hamm 1990, 1090-1093.

Starowieyski M., Wstęp, w: Muza łacinska. Antologia poezji wczesnochrześcijańskiej i średniowiecznej (III-XIV/XV w.), opr. M. Starowieyski, Wrocław - Warszawa -Kraków 2007, XI-CIV.

\section{Przekład}

\section{[Oratio ad Deum] ${ }^{4}$}

O Deus aeterne, mundi sanctissime Rector, Te mea mens ambit, animaeque ac vivida virtus,

Laus, amor atque decus, cordis tu lumen honestum.

Membrorum gestum, tu oculorum reddis et usum,

Auribus auditum, manibus opus indis amatum. Quidquid tellus habet, pontus atque aethera claudunt,

Et quidquid sentit, sapit, est, et vivit ubique.

Omnia nempe tua sapientia condita fulsit

Vivificat, servat, valido et regit omnia nutu.

Fac me, summe pius, toto te corde fateri

Te sermone loqui, te discere dogmate recto,

Quaerere te manibus, pura te et mente precari.

Tu via, tu virtus, tu vita et ianua vitae,

Tu merces operis, tu factor, tu quoque doctor.

Da mihi nunc veniam misero, et mea crimina laxa:

Fac me velle bonum, scire actu, et rite probare, Sicque tuum laetum tribuas tunc cernere vultum, Perpetuo, et vera me gaudia carpere fructu.

\section{[Modlitwa do Boga]}

O Boże wieczny, co jesteś rządcą wszechświata najświętszym,

Do Ciebie dążą me myśli i siła żywotna duszy.

Chwało, miłości i piękno, Tyś serca światłem szlachetnym,

Ty moim członkom ruch dajesz i oczom moim widzenie,

Mym uszom zdolność słyszenia, ręce me wprawiasz do pracy,

Cokolwiek żyje na ziemi, mieści powietrze i morze,

Cokolwiek czuje, rozumie, istnieje i wszędzie żyje,

Wszystko to Twoja mądrość swym blaskiem opromieniła,

Ożywia to, zachowuje i rządzi mocnym skinieniem.

O daj, najłaskawszy Boże, całym Cię sercem wyznawać,

O Tobie mówić słowami i Ciebie uczyć się szczerze,

I Ciebie rękami szukać, i czystą prosić Cię duszą.

Ty jesteś życiem, Tyś mocą, Tyś życiem i bramą życia,

Ty jesteś za trud nagrodą, mym stwórcą, nauczycielem.

4 Utwór napisany heksametrem. Przekład na podstawie: Hrabani Mauri carmina XII, MGH Antiquitates. Poetae Latini medii aevi, 2: Poetae Latini aevi Carolini, Berolini 1884, 174-175 (dalej: Poetae Latini). 


\section{De cruce 5}

Vexillum Domini qui vicit tartara Christi, En rubet hic pictum luce micando nova. Quisquis hanc cernis, laetus tu dicito Christo Semper in aeternum gloria magna Deo.

Item $^{6}$

Crux veneranda Dei solis haec fulget ab ortu, Mitigat haec Austri minitantia flabra procellas. Haec Zephyri nimbos et flumina pellit ab aede, Haec Boreae gelidos compescit frigora flatus. Christe pius Dominus, visum cor dirige dextra, Verba Deus famulo redde probata tuo.

\section{De cruce ${ }^{7}$}

Crux micat alma Dei, divino munere plena, Sanguine quam Christus consecrat ipse suo. Quam precor astantes cuncti cunctique sedentes, Condigna laude semper amate piam.
O, daj mi swe przebaczenie i odpuść mi moje winy, Spraw, abym dobra pragnął, poznał je i go doświadczył,

W ten sposób zobaczył kiedyś Twoje pogodne oblicze

Oraz kosztował na wieki moich prawdziwych radości.

\section{O krzyżu}

To sztandar Chrystusa Pana, co moc Tartaru pokonał.

Spójrz! Zdobi go szkarłat krwi, nowy lśni na nim blask.

Ty, spoglądając na niego, mów do Chrystusa radośnie:

„Bogu wielkiemu cześć niechaj na wieki brzmi”.

\section{Utwór na ten sam temat}

Boży krzyż tak czcigodny jaśnieje od wschodu słońca.

Uśmierza on groźne burze, które gna Auster z południa.

Odpędza on od świątyni chmury Zefiru z ulewą, On Boreasza poskramia i jego mroźne podmuchy.

Chryste, nasz Panie łaskawy, prawicą swą sercem mym kieruj,

I za modlitwę mą słowem odpłać mi swym.

\section{Utwór na ten sam temat}

Lśni blaskiem krzyż życiodajny, co Bożej łaski jest pełen,

Bo Chrystus uświęca go strugami własnej swej krwi.

Wszystkich stojących wokół i wszystkich siedzących proszę,

Zawsze kochajcie krzyż, godny niosąc mu hołd.

5 Utwór w metrum elegijnym. Przekład na podstawie: Hrabani Mauri carmina LXII, w: Poetae Latini, 222.

6 Utwór napisany heksametrem, ostatni wers - pentametrem. Przekład na podstawie: Hrabani Mauri carmina LXII, w: Poetae Latini, 222.

7 Utwór w metrum elegijnym. Przekład na podstawie: Hrabani Mauri carmina LXIV, w: Poetae Latini, 223. 


\section{Item $^{8}$}

Qui cruce confixus praestavit dona salutis, Vos corde et carne protegat atque regat. Consilium prudens tribuat atque utile verbum, Actum pacificum, tempus et omne bonum.

\section{Utwór na ten sam temat}

Chrystus przybity do krzyża, co przyniósł dary zbawienia,

Waszych niech strzeże serc i niech prowadzi was.

Niech da wam radę roztropną i słowo da wam przydatne,

By spokojny był trud, by szczęśliwy był czas.

\section{Item $^{9}$}

\section{Utwór na ten sam temat}

Qui cruce confixus renovavit sanguine mundum, Chrystus przybity do krzyża świat cały krwią Per crucis hoc signum hanc dicet ipse domum. swą odnowił,

Niech przez krzyża ten znak On uświęci ten dom.

\section{Item $^{10}$}

Crux haec sancta Dei consignet munera mensae, Te oto dary na stole krzyż Boży niechaj naznaczy, Divino dono pocula cum dapibus.

Et pater ipse sedens expenso munere largus

Sis inopi, semper hospitis esto memor.
Błogosławieństwem niech swym uświęci każde z tych dań.

Ty, ojcze, gdy przy nim siedzisz, bądź hojnym dla ubogiego,

I zawsze pomnij, by gość pod dach twój stale mógł wejść.

\section{Item $^{11}$}

En crux alma Dei venerando fulget amictu, Quae Salvatoris tincta cruore fuit.

Hanc, precor, orate submissi, dicite laudes, A Christo domino poscite lucis opem.

\section{Utwór na ten sam temat}

Oto krzyż tak hojny życiem lśni wspaniale ozdobiony -

Krzyż skąpany kiedyś w krwi, co płynęła z Pańskich ran.

Przed nim módlcie się więc kornie, jego chwałę ogłaszajcie,

Proście, aby Chrystus Pan swej światłości dał wam dar.

8 Utwór w metrum elegijnym. Przekład na podstawie: Hrabani Mauri carmina LXIV, w: Poetae Latini, 223.

9 Utwór w metrum elegijnym. Przekład na podstawie: Hrabani Mauri carmina LXIV, w: Poetae Latini, 223.

10 Utwór w metrum elegijnym. Przekładu dokonano na podstawie: Hrabani Mauri carmina LXIV, w: Poetae Latini, 223.

11 Utwór w metrum elegijnym. Przekład na podstawie: Hrabani Mauri carmina LXIV, w: Poetae Latini, 223. 
Ad crucem erga altare positam ${ }^{12}$

Pars crucis hic domini est, qua Christus secla be- Tu oto jest cząstka krzyża, przez krzyż Pan świat avit,

Portio sudarii chlamydis atque sacrae.

Papa en Gregorius, Martinus praesul et almus, Ambrosius doctor atque Medardus ovant.

Maximinus adest, Germanus, hicque Remigius Virgine cum insigni et martyre Anastasia.

\section{Do krzyża umieszczonego przy oltarzu}

Chusty grobowej część i część ze świętych szat.

Tu także jest papież Grzegorz i Marcin, biskup pobożny,

Mądry Ambroży jest tu, z Medardem ciesząc się wraz.

Jest tu Maksymin i German i jest tu także Remigiusz

I Anastazja wraz z nim - dziewic męczennic wzór.

\section{Ad crucem in medio ecclesiae ${ }^{13}$}

Pars crucis hic domini est, qui summus regnat in arce

Sanguine qui fuso saecla beavit ovans.

Hic Michael gaudet, simul et Baptista Joannes, Insignesque viri martyrio placiti.

Hic sanctus Stephanus, Fabianus cum Cyriaco Atque Sebastiano martyrio rutilant.

Hic Benedictus ovat, hic papa Gregorius astat Suscipiunt vota atque Deo referunt.

\section{Do krzyża na środku kościoła}

Tu oto jest cząstka krzyża Pana, co w niebie króluje,

On to, przelawszy swą krew, chciał uszczęśliwić ten świat.

Tutaj raduje się Michał pospołu z Janem Chrzcicielem

I święci mężowie są tu, i męczenników jest chór.

Jest święty Szczepan i Fabian z Cyriakiem oraz Sebastian -

O jak wspaniale lśni złoty męczeństwa złoty blask! Tutaj się cieszy Benedykt i papież Grzegorz tu stoi, Modlitw słuchając i próśb, przed Boży niosą je próg.

12 Utwór w metrum elegijnym. Przekład na podstawie: Hrabani Mauri carmina LXXVII, w: Poetae Latini, 230. Treścią utworu jest napis znajdujący się w kościele św. Wigberta Wyznawcy we wschodniej absydzie, gdzie spoczywa ciało świętego. Por. Hrabani Mauri carmina LXXVII, w: Poetae Latini, 228. W przypisie do wydania oryginału zob. komentarz mówiący o tym, że kościół ten został poświęcony przez Rabana, arcybiskupa Moguncji 28 X 850 roku.

13 Utwór w metrum elegijnym. Przekład na podstawie: Hrabani Mauri carmina LXXX, w: Poetae Latini, 232-233. 


\section{Versus isti sunt scripti in ara capellae ${ }^{14}$}

Expansis manibus sic totum amplectitur orbem In cruce confixus Christus in arce Deus.

Exstinxit mortem, confregit sceptra tyranni

Aeternam requiem reddidit ipse suis.

\section{Wersety napisane na oltarzu kaplicy}

Oto ręce wyciągnięte, co świat cały obejmują Tu na krzyżu wisi Ten, który tron swój w niebie ma. On śmierć samą unicestwił, On tyrana berło złamał I każdemu z wiernych swych pokój wieczny raczył dać.

\section{Epitaphium Hludarii Imperatoris ${ }^{15}$}

Continet hic tumulus memorandi Caesaris ossa, Hlotharii magni, principis atque pii.

Qui Francis, Italis, Romanis praefuit ipsis, Omnia sed sprevit, pauper et hinc abiit.

Nam bis tricenos monachus sic attigit annos, Et se mutavit, ac bene post obit.

II Kal. Octob ${ }^{16}$

\section{Ymnus de natali Domini metro trochaico tetrametro scriptus ${ }^{17}$}

Lumen clarum rite fulget orto magno sydere, quod per totum splendet orbem,

\section{Epitafium cesarza Lotara}

Leży tu niezapomniany, wielki i łaskawy Cezar Oto kości, oto grób, tu na wieki spoczął już.

Chociaż Frankom on przewodził i Italom, i Rzymianom,

On to wszystko za nic miał i ubogi odszedł stąd.

Został mnichem i w tym stanie dożył tu lat sześćdziesięciu,

Wraz ze stanem zmienił strój i pobożnie zaraz zgasł.

w przeddzień kalend październikowych

\section{Hymn o Narodzeniu Pańskim tetrame- trem trochaicznym napisany}

Jasne światło lśni dostojnie,

Oto wielkiej gwiazdy wschód,

Blask jej spowił całą ziemię

14 Utwór w metrum elegijnym. Przekład na podstawie: Hrabani Mauri carmina LXXX, w: Poetae Latini, 234. Treścią utworu jest napis z kościoła św. Saturnina. Por. Hrabani Mauri carmina LXXX, w: Poetae Latini, 232.

15 Utwór w metrum elegijnym. Przekład na podstawie: Hrabani Mauri carmina XCI, w: Poetae Latini, 241.

16 Lotar I (795-855), najstarszy syn Ludwika I Pobożnego, król Franków, święty cesarz rzymski. Przed śmiercią podzielił państwo między trzech synów: Ludwika II, Lotara II i Karola z Prowansji, po czym wstąpił do opactwa benedyktyńskiego w Prüm, gdzie bardzo szybko zmarł. Por. McKitterick, Królestwa Karolingów 751-987. Władza - konflikty - kultura, PWN, Warszawa 2016, passim.

17 Przekład na podstawie: Hrabani Mauri carmina. Hymni incertae originis II, w: Poetae Latini, 245-246. 
umbras noctis aufugans.

Christo nato Rege magno, totus orbis gaudeat.

Dux de Iuda, quem propheta

olim iam praedixerat, laetus nobis esse venit, Bethlem nascens inclyta.

Christo nato Rege magno, totus orbis gaudeat.

Hunc regalis virgo mater, partu gaudens edidit. quem Gabrihel nuntiavit, salvatorem gentium.

Christo nato Rege magno, totus orbis gaudeat.

Cum pastores excubantes cura mordet nam gregis, Clarus ipsos ad laetandum, exhortatur nuntius.

Christo nato Rege magno, totus orbis gaudeat.

Concinebat angelorum, turba laeta laudibus. terrae pacem praedicantes, caelo reddunt gloriam. Christo nato Rege magno, totus orbis gaudeat.

$\mathrm{O}$ stupendum mirandumque sacramentum gloriae, quod tonantem supra cuncta, virgo gestat parvula.

Christo nato Rege magno, totus orbis gaudeat.

Factor caeli, terrae factor vulva est clausus feminae, auctor summus angelorum, fit praesepe conditus.
I rozprasza nocy mrok.

Ciesz się, ciesz się, ziemio cała, Bo się rodzi Chrystus Król.

To wódz z Judy - o Nim prorok Już tak dawno głosił wieść, Idzie, by nas rozradować, I z Betlejem Jego ród.

Ciesz się, ciesz się, ziemio cała, Bo się rodzi Chrystus Król.

Matka - Panna Go zrodziła, A królewski jest Jej szczep. Jako pogan Zbawiciela Gabriel Go zwiastował sam. Ciesz się, ciesz się, ziemio cała, Bo się rodzi Chrystus Król.

Gdy pasterze straż trzymają, Śpiąc tej nocy wśród swych stad, Oto zwiastun promienisty Wielką radość głosi im. Ciesz się, ciesz się, ziemio cała, Bo się rodzi Chrystus Król.

I pochwalny hymn radośnie Chór aniołów śpiewał tam, Ziemi pokój ogłaszając, Wznosząc chwałę w nieba strop. Ciesz się, ciesz się, ziemio cała, Bo się rodzi Chrystus Król.

Niepojęta i przedziwna

Tajemnica chwały jest:

Skromne Dziewczę nosi Tego, Który ciska w ziemię grom. Ciesz się, ciesz się, ziemio cała, Bo się rodzi Chrystus Król.

Stwórca nieba, ziemi Stwórca

W ludzkie łono wstąpił chciał I choć Panem jest aniołów, Mieści Go niewielki żłób. 
Christo nato Rege magno, totus orbis gaudeat.

Palmo caelum qui metitur, terram claudit pugili, pannis paucis obvolutus, infans vagit parvulus.

Christo nato Rege magno, totus orbis gaudeat.

Quae divisit lucem ab umbris, summi primum dextera, matris mammas ecce tractat, lactis potum quaesitans. Christo nato Rege magno, totus orbis gaudeat.

Os praeclarum Conditoris, quod formavit saeculum, en admotum nunc libenter sugit matris ubera.

Christo nato Rege magno, totus orbis gaudeat.

O beata mater Christi, David stirpis femina. tu laus orbis et regina, laeta virgo Maria.

Christo nato Rege magno, totus orbis gaudeat.

Votis adsis tu piorum, omne servans saeculum. patriarchis et prophetis laus corona gloriae.

Christo nato Rege magno, totus orbis gaudeat.

Ecce sperant laetabunda, angelorum agmina.

Christi plebem quod gubernes,
Ciesz się, ciesz się, ziemio cała, Bo się rodzi Chrystus Król.

Ten, co dłonią mierzy niebo, Ziemię chowa w garści swej, Pieluszkami jest spowity I niemowlę małe łka.

Ciesz się, ciesz się, ziemio cała, Bo się rodzi Chrystus Król.

On prawicą swą oddzielił

Od światłości ciemny mrok -

Dziś dotyka piersi Matki,

Bo się napić mleka chce.

Ciesz się, ciesz się, ziemio cała, Bo się rodzi Chrystus Król.

Te przesławne usta Stwórcy, Co nadały światu kształt, Przytulone są do Matki

I skwapliwie ssą Jej pierś.

Ciesz się, ciesz się, ziemio cała, Bo się rodzi Chrystus Król.

Szczęsna Matko Chrystusowa, Dawidowy jest Twój ród, Świata chlubo i królowo, Panno Mario, ciesz się, ciesz.

Ciesz się, ciesz się, ziemio cała, Bo się rodzi Chrystus Król.

Przyjdź z pomocą swoim wiernym,

Ocalając cały świat,

Patriarchów i proroków

Wszystkich chwała wieńczy Twa.

Ciesz się, ciesz się, ziemio cała,

Bo się rodzi Chrystus Król.

Ucieszeni aniołowie

W Tobie mają ufność swą,

Że Ty ludem Pana rządzisz, 
archanorum conscia.

Christo nato Rege magno,

totus orbis gaudeat.

Nam te, virgo caelebs nupta,

sexus omnis appetit.

Tu parentes atque natos

deprecando protege.

Christo nato Rege magno,

totus orbis gaudeat.

Gaudet caelum cum supernis

angelorum milibus,

omnis terrae plenitudo,

pontus, astra, flumina.

Christo nato Rege magno,

totus orbis gaudeat.

\section{Hymnus de Epiphania ${ }^{18}$}

En caeli rutilant lumina splendida ${ }^{19}$ testantur dominum nascere parvulum, qui format minima et creat ardua, regni sceptra tenens, est deus atque homo.

Duxit stella magos mystica quaerere, Regis pacifici rite cunabula.

Quem Iudaea tenens orbis in ultima, Diffusis radiis nunciat inclyta.

Herodes capiens impius auribus, quod Rex hic fuerat natus in urbibus Iudaeae, hunc citius quaerere praecipit tristis, moxque neci tradere destinat.
Znając Boga tak jak nikt.

Ciesz się, ciesz się, ziemio cała,

Bo się rodzi Chrystus Król.

Ciebie, Panno poślubiona,

Prosi kornie wszelki stan:

Chroń rodziców oraz dzieci,

Wspieraj ich modlitwą swą.

Ciesz się, ciesz się, ziemio cała,

Bo się rodzi Chrystus Król.

Już się cieszy z tysiącami

Anielskimi nieba dwór,

Ziemia wraz z jej mieszkańcami,

Morze, rzeki, gwiezdny rój.

Ciesz się, ciesz się, ziemio cała,

Bo się rodzi Chrystus Król.

\section{Hymn o Epifanii}

Już złocą się światła promienne na niebie, To znak, że się rodzi nasz Pan malusieńki. On rzeczy najmniejsze i wielkie kształtuje, Ma berło królestwa - jest Bogiem-człowiekiem.

Gwiazda tajemnicza prowadziła mędrców,

By Króla kołyski właściwie szukali,

A On na świat przyszedł w dalekiej Judei,

Co blaskiem skąpana tę nowinę głosi.

Gdy Herod bezbożny posłyszał wieść o tym, Że w mieście judejskim ów Król się narodził, Zgnębiony rozkazał, by szukać Go prędko I wnet wydał wyrok, na śmierć Go skazując.

18 Utwór w metrum asklepiadejskim mniejszym. Przekład na podstawie: Hrabani Mauri carmina. Hymni incertae originis IV, w: Poetae Latini, 247.

19 Lumina splendida - w tym miejscu, wbrew lekcji lumine splendida zamieszczonej w MGH, idę za lekcją znajdującą się w: Analecta hymnica medii aevi. L. Hymographi Latini. Lateinische Hymnendichter des Mittelalters, red. G.M. Dreves - C. Blume, Leipzig 1907, 189. 
Inventus dominus indice sidere est, in Bethleem pariter cumque parentibus cui mox ergo magi munera deferunt, thus, myrrham, aurum ab Ophir, regi, homini, deo. I złoto z Ofiru - to Bóg, król i człowiek.

Huic, trux ipse licet saeviat horride, Herodes iubeat caedere parvulos, regnum rite suum firmiter undique, Servatur, domino corruit invidus.

En est ista dies munere nobilis, baptismo haec domini nobilis exstitit quod vinum dominus fecerat ex aqua, commendat placide haec sacra dogmata.

Gaudemus pariter mentibus en precor, quod nobis dominus hic pius advenit, quod nostra voluit munera sumere, quod baptisma dedit, pocula contulit.

Nam rex Christus adest orbis et arbiter, lux de luce pia, et Pater omnium. qui nos ad patriam ducat et optimam, et vitae faciat gaudia metere.

\section{Hymnus in Epiphania ${ }^{20}$}

Venit Deus factus homo, exsultet omnis natio. caelum dedit sidus novum, apparet auctor omnium.

Magi ferebant munera, primi legati gentium, quae cum sacro mysterio signant latentis gloriam.

Aurum potentis regmina, numen sacrum thus indicat, carnemque myrrha mortuam, mundi piantem machinam.
Pan zaś dał się znaleźć za gwiazdy przewodem W Betlejem, a wraz z Nim i Jego rodzice, Mędrcy niosą dary - kadzidło i mirrę,

Choć Herod się sroży na Niego straszliwie I wydaje rozkaz, by zabijać dzieci, To Jego królestwo zostanie nietknięte, A władca zawistny ulegnie przed Panem.

Dzień ten jest oto darami przesławny Bo Pan w tym dniu właśnie zechciał być ochrzczony, Także wodę w wino w tym dniu Pan przemienił, Święte tajemnice ten dzień przypomina.

Cieszymy się wspólnie, weselą się dusze, Bo przybywa tutaj do nas Pan łaskawy, Bo On naszych darów nie wzbraniał się przyjąć, Bo chrzest nam zostawił i dał stągwie wina.

Bo Chrystus jest królem i sędzią jest świata, Światłością z światłości i Ojcem wszechrzeczy, Niech nas do ojczyzny prowadzi najlepszej, Niech życia wiecznego radości da zbierać.

\section{Hymn na Epifanię}

Bóg-człowiek do nas przychodzi, Niech wszystkie ludy się cieszą, Na niebie nowa lśni gwiazda,

Zjawia się Stwórca wszechrzeczy.

Nieśli Mu dary magowie -

Ci pierwsi pogan posłańcy,

A dary te tajemniczo

Chwałę ukrytą wskazują.

Złoto to władza królewska,

Kadzidło to świętość bóstwa,

Mirra to ciało śmiertelne,

Co świata ogrom odkupi.

20 Utwór napisany dymetrem jambicznym akatalektycznym. Przekład na podstawie: Hrabani Mauri carmina. Hymni incertae originis V, w: Poetae Latini, 248. 
Herodes, hostis invidus, ignorat haec trucissimus, Christus saluti gentium, quae sic ministrat providus.

Iesu precamur optime, tu nos benignus dirige. prompti feramus quod tibi laudis sacrata munera.

\section{Item alius ${ }^{21}$}

Christus Redemptor plebium baptisma consecrat novum. venite cuncti criminum: lavare sordes omnium.

Iordanis amnem dedicat salvator undas expians, fontes abyssi flumina, consecrat orbis artifex.

Fletus amaros fundite, mentis secreta pandite, salsae per ora lacrymae dulcem salutem praeparent.

Fex nulla nos coinquinet, mortis vetustae portio. sed lucis alma mansio vitam perennem conferat.
Herod zawistny, straszliwy, Wróg groźny - nic nie wie o tym, Że dla ludzkiego zbawienia

Chrystus przychodzi na ziemię.

Prosimy Cię, Jezu drogi, Ty nami kieruj łaskawie, Chcemy ochoczo nieść Tobie Dar święty ku Twojej chwale.

\section{Inny utwór na ten sam temat}

Chrystus, co lud chce odkupić, Chrzest nowy dziś ustanawia.

Przyjdźcie, o wszyscy grzesznicy, By z wszelkich brudów się obmyć.

Uświęca wody Jordanu, Moc zbawczą dając ich falom, Źródła i rzeki głębokie

Uświęca Stworzyciel świata.

Porzućcie gorzkie szlochania, Otwórzcie serc waszych głębie, Niech strugi słonych łez płyną, Słodkie zbawienie gotując.

Niech żaden brud nas nie plami Śmierci pradawnej następstwo, Lecz światłość błoga w nas mieszka I w wieczne życie wprowadzi.

\section{Z języka łacińskiego przełożył wstępem i komentarzem opatrzył ks. Tadeusz Gacia ${ }^{22}$}

21 Utwór napisany dymetrem jambicznym akatalektycznym. Przekład na podstawie: Hrabani Mauri carmina. Hymni incertae originis VI, w: Poetae Latini, 248.

22 Ks. dr hab. Tadeusz Gacia, prof. KUL, kierownik Katedry Filologii Łacińskiej w Instytucie Studiów Klasycznych i Orientalnych na Wydziale Nauk Humanistycznych Katolickiego Uniwersytetu Lubelskiego Jana Pawła II, dyrektor Instytutu; e-mail: tadeusz.gacia@kul.lublin.pl, ORCID: 0000-0002-1836-9506. 